\title{
Deciphering and Embodying Contemporary Piano Scores: A Commentary on Huisman, Gingras, Dhondt, and Leman (2017)
}

\author{
JENNIFER MACRITCHIE[1] \\ The MARCS Institute for Brain, Behaviour and Development, Western Sydney University, Australia
}

\begin{abstract}
Rehearsing a new contemporary notated piano score often requires the performer to dedicate a large amount of time to translating the notation: tasks may include interpreting new symbols, or old symbols in new contexts, learning new extended techniques, and learning the link between symbol and physical gesture. Huisman et al's article details an experiment that studies the use of various types of music editions and their effect on the practice and performance of contemporary piano music scores. This commentary considers the following issues when discussing the interpretation of unfamiliar piano scores: 1) issues in reading notation that arise from performance practice challenges, 2) cultivating an interpretive platform, and 3) embodiment in the rehearsal of a new, contemporary score.
\end{abstract}

Submitted 2016 June 16; accepted 2017 February 14.

KEYWORDS: notation, embodiment, rehearsal, contemporary performance practice

REHEARSING and interpreting contemporary piano scores is a complex, challenging and sometimes intimidating world for the performer. Although the target article uses participants who are experienced with the interpretation and performance of this type of material, issues in rehearsal of contemporary music are pertinent also for those with relatively little performing experience in the genre. Moving beyond an established performance practice found in Western classical music, contemporary scores often open up the interpretive possibilities both at an instrument level and at a musical conceptual level. With this shift comes challenges for the performer, one of which is the segmentation and translation of more dense and/or complex score markings to physical gestures. Huisman and colleagues attempt to ease this particular challenge by examining the benefit of using a specially designed "embodied" edition over the original score, to look at how this impacts both the amount of rehearsal time and the number of errors made in a subsequent performance. Literature that examines the rehearsal and performance of contemporary works is sparse, despite a few notable exceptions (Barrett, 2014; Clarke et al, 2005; Clarke \& Doffman, 2014; Viney \& Blom, 2015), and so this article is a welcome contribution that begins to examine how performers decipher and interpret contemporary score information. Demonstrating that an embodied score aids the performer's rehearsal touches on a number of areas within the practice and performance of contemporary music, which this commentary will discuss.

\section{STAGES OF PRACTICE WITH CONTEMPORARY PIANO SCORES}

In preparing a notated piece for performance, a performer will go through various stages of taking apart the piece bit by bit, working on the separate parts, and piecing it back together again (Chaffin \& Imreh, 2002). For a Western classical score, this encompasses stages of first reading, taking the piece section by section, and then developing a narrative. In contemporary scores, however, the performer cannot rely on established performance practice in order to decipher the notation. There is an established connection in Western classical performance practice between a scored note and the gestures used to reproduce this note on the instrument (otherwise referred to as the sound-producing gesture, Jensenius et al, 2010). For contemporary scores, this intended connection can change from composer to composer, with the type and style of notation open to large variation. Although graphic scores provide a case in point, where much of the pitch and duration information 
is indeterminate (Thomas, 2007), this variation also applies to more traditionally notated pieces. Kanno's (2007) stages of rehearsing a contemporary piece incorporate this to an extent: first performers learn the pitch and rhythm, then coordinate this with the body, then create an interpretation. Contemporary performers (and particularly novices) require these extra stages of rehearsal in order to decipher the notation and translate this into the sound-producing gestures. Of course this act of translation and how it connects with the later stage of interpretation will depend on whether the notation itself is describing the sound (descriptive) or the action (prescriptive) (Kanno, 2007). As the target article uses fragments from Sorabji's scores that resemble traditional descriptive notation, this commentary will focus on this type.

Translating the notation in this first stage can be time-consuming, even when the notation may make use of symbols that are well known to the performer. With descriptive scores having a propensity for dense amounts of information (to ensure this 1-to-1 relationship between notation and sonic outcome as the authors refer to Stockhausen's Klavierstücke), it is common practice for contemporary performers to spend time rewriting score segments (Thomas, 2007), presumably to make the final result (i) more readable and (ii) more physically playable - a performing edition. This appears to be the assumption upon which Huisman and colleagues create these different embodied editions. By providing a suggested reading of the information translated into a form that is more easily embodied, performers can spend time physically rehearsing the score rather than re-writing various sections in order to come to a similar result. That the performing editions in the target article significantly reduced the study time needed to commit the musical material to memory implies that these translating notations and coordinating of the body stages are made more efficient for the performers.

In making these first two stages more efficient, if we are also to assume that the interpretation stage follows sequentially and is not done in parallel, these editions point towards a way that performers can get to grips with meaning formation faster. It would be interesting to note the performers' analyses of the score segments and their intentions for performance that evolve throughout a rehearsal period to see if there are any effects of edition type either on the number or type of interpretive thoughts. The authors' suggestion of limiting practice time across performers could help shed light on this stage. Bringing out patterns that are already inherent in the notation, whether it be by marking different voices or editing fingerings or hand distribution, is ultimately a practical help to performers who are unfamiliar with contemporary scores. It may also help in memorization of the material such that features are already organised into performance cues (Chaffin et al, 2010). The question arises as to whether there are beneficial processes at work during this translation stage that are being sidelined. One performer noted that the rhythmic aids in the Adagio segment made him feel "lazy". Does the challenge in having to thoroughly analyse the score before performance, or in the act of re-writing out the notation, stimulate performers to better understand and memorise the material? There was no clear effect of the editions on the number of score markings made by the performers, or indeed on the number of errors produced which would suggest that this isn't the case. However, again with controlled practice time across the set of pianists, it would be interesting to test the effect of the different editions against the amount of notes produced by the performers, and consequently their memory of the segment.

\section{CULTIVATING AN INTERPRETIVE PLATFORM}

With classical Western scores, performance practice often dictates how a note should be performed, however, in contemporary notation with a wide variety of score-types, emblems and differing uses of these emblems by different composers, as Huisman and colleagues note, it can be more than a one-to-one translation. Even in the subset of contemporary pieces that can be classes as notated music, there are vast differences in the use of traditional features such as bar lines and dynamics amongst composers. Philip Thomas (1999) provides a particular example contrasting Messaien's use of bar lines in indicating phrasing units with examples from Stockhausen's Klavierstücke I and II, which demonstrate the use of bar lines to mark changes in rhythm or tempo.

To resolve such issues, a performer can find use in building an interpretational platform (Viney \& Blom, 2015). Although this includes steps that are similar to what is expected when interpreting Western classical music (e.g. researching the background of the composer, listening to other performances of the same work), the scarcity of performance practice knowledge in contemporary music can often make this stage all the more important. An appreciation of the composer's works provides hints in choosing particular features that have been left undetermined (tempo, dynamics, pitch, duration) as well as an idea of where in the score the performer can exercise their own creative input (Thomas, 2007). Extra-musical information such as background information about the composer and the piece (e.g. the meaning of the title) can aid the 
performer's interpretive choices. The edits on Sorabji's scores in the target article served to answer technical questions of fingering, rhythm and hand distribution. In some cases, analytic information was provided with voices highlighted in different colours. However, providing further information to establish this interpretive platform would perhaps allow an investigation of this final stage of rehearsal. Urchueguía (2006) writes that it is the editor's task "not to limit artistic freedom of the interpreter but to offer them a framework with which to understand the notation". Providing extra-musical information could be the key to understanding not only how to reproduce specific technical features within the score, but also to interpret the score as a whole.

\section{THE BODY AS MEDIATOR}

Deciphering the notation from a score and producing the necessary physical actions may not occur purely in serial stages, one following the other. Embodied music cognition theory states that just as physical actions can influence the mind, this process can work in reverse. The body is the mediator between the musician's mental representation of a piece of music and the physical actions they produce in order to realise this representation (Leman, 2008). In Western classical music performance we see that performers embody the phrasing structure and emotional content of a piece (Davidson, 1993; Thompson \& Luck, 2012; Vines et al, 2006), not necessarily in the exact same way, but certainly with the same oscillatory behaviour reflecting the phrasing structure (Buck, MacRitchie, \& Bailey, 2013; MacRitchie, Buck, \& Bailey, 2013). Although contemporary classical music is known to focus on sounds and moments rather than phrases and sections, performers still seek out ways to segment the piece they perform (Heaton, 2012), and so it follows that they may still embody their representation of the music in such sections. In the particular score segments referred to in Husiman et al's article, there is a dense amount of notes that need to be segmented in terms of their rhythm (i.e. into beats) as well as into various voices. As the authors suggest, the embodied versions of the score segments may help performers in this way by visually separating notes such that they better resemble learned patterns of the performers, which they can easily translate to movements.

Gestures may be used in performance and developed in rehearsal for a number of functions, not least in ensemble situations where they benefit communication between co-performers (Davidson \& Correia, 2002; Ginsborg \& King, 2009). There are few studies which detail the occurrence of these gestures in rehearsal and how they develop over time, whether in solo or ensemble performance. The majority of the literature focuses on the finished product - the performance. If we take an embodied cognition approach, documenting where (in the score) and when (throughout the rehearsal process) a gesture is formed, or the physical actions change (for instance monitoring how two segments of a piece are connected together) may provide details on how a score is being processed and understood by the performer. The authors suggest that the effect of the editions on the rehearsal time taken by the performers is due to the embodied scores speeding up the translation of notes into physical gestures. The precise effect of the editions could be analysed in terms of occurrence and fluency of physical gestures over a set rehearsal period. These physical gestures could be measured either directly through motion capture, or indirectly through measurements of the sound output (e.g. expressive timing via MIDI information).

\section{CONCLUSION}

Huisman and colleagues show that an 'embodied' edition of a contemporary work has a minimising effect on the amount of rehearsal time needed to commit a piece to memory. This study opens up various questions concerning the rehearsal and performance of unfamiliar scores. The authors suggest that this reduction in rehearsal time is a streamlining of the deciphering notation stage such that the performer can quickly grasp patterns present in the score both mentally and physically. However, suggestions for further work controlling for rehearsal time and analysing performer thoughts throughout rehearsals would help determine how an interpretation of each score segment is formed in relation to the written material available. Finally, by examining the physical features of embodiment across rehearsals via audio and motion analysis, details could be obtained on how and when a performer's mental representation is developed as a result of different editions. 


\section{NOTES}

[1] Correspondence can be addressed to: Dr Jennifer MacRitchie, The MARCS Institute for Brain Behaviour and Development, Western Sydney, Locked Bag 1797, Penrith, 2751, NSW, Australia. j.macritchie@westernsydney.edu.au.

\section{REFERENCES}

Barrett, M. S. (2014). SEMPRE studies in the psychology of music: Collaborative creative thought and practice in music. Farnham, Surrey; Burlington, VT: Ashgate.

Buck, B., MacRitchie, J., \& Bailey, N. J. (2013). The interpretive shaping of embodied musical structure in piano performance. Empirical Musicology Review, 8(2), 92-119. https://doi.org/10.18061/emr.v8i2.3929

Chaffin, R., \& Imreh, G. (2002). Stages of practice revisited. In R. Chaffin, G. Imreh, \& M. Crawford (Eds.), Practicing perfection: Memory and piano performance (pp. 239-246). Mahwah, NJ: Lawrence Erlbaum Associates.

Chaffin, R., Lisboa, T., Logan, T., \& Begosh, K. T. (2010). Preparing for memorized cello performance: The role of performance cues. Psychology of Music, 38(1), 3-30. https://doi.org/10.1177/0305735608100377

Clarke, E., Cook, N., Harrison, B., \& Thomas, P. (2005). Interpretation and performance in Bryn Harrison's "être-temps." Musicae Scientiae, 9(1), 31-74. https://doi.org/10.1177/102986490500900102

Clarke, E., \& Doffman, M. (2014). Expressive performance in contemporary concert music. In D. Fabian, R. Timmers, \& E. Schubert (Eds.), Expressiveness in music performance: Empirical approaches across styles and cultures. New York: Oxford University Press.

https://doi.org/10.1093/acprof:oso/9780199659647.003.0006

Davidson, J. W., \& Correia, J. (2002). Body movement. In R. Parncutt \& G. E. McPherson (Eds.), The science and psychology of music performance: Creative strategies for teaching and learning (pp. 237-250). New York: Oxford University Press. https://doi.org/10.1093/acprof:oso/9780195138108.003.0015

Davidson, J. W. (1993). Visual perception of performance manner in the movements of solo musicians. Psychology of Music, 21(2), 103-113. https://doi.org/10.1177/030573569302100201

Ginsborg, J., \& King, E. (2009). Gestures and glances: The effects of familiarity and expertise on singers' and pianists' bodily movements in ensemble rehearsals. In J. Louhivuori, T. Eerola, S. Saarikallio, T. Himberg, \& P.S. Eerola (Eds.), 7th Triennial Conference of European Society for the Cognitive Sciences of Music, (pp. 159-164). Jyväskylä, Finland: University of Jyväskylä.

Heaton, R. (2012). Contemporary performance practice and tradition. Music Performance Research, 5, 96104.

Jensenius, A. R., Wanderley, M. M., Godøy, R. I., \& Leman, M. (2010). Concepts and methods in research on music-related gestures. In R. I. Godøy \& M. Leman (Eds.), Musical gestures: Sound, movement, and meaning (pp. 12-35). New York: Routledge.

Kanno, M. (2007). Prescriptive notation: Limits and challenges. Contemporary Music Review, 26(2), 231254. https://doi.org/10.1080/07494460701250890

Leman, M. (2008). Embodied music cognition and mediation technology. Cambridge, MA: The MIT Press.

MacRitchie, J., Buck, B., \& Bailey, N. J. (2013). Inferring musical structure through bodily gestures. Musicae Scientiae, 17(1), 86-108. https://doi.org/10.1177/1029864912467632 
Thomas, P. (2007). Determining the indeterminate. Contemporary Music Review, 26(2), 129-140. https://doi.org/10.1080/07494460701250866

Thomas, P. (1999). Interpretive issues in performing contemporary piano music. PhD Thesis, University of Sheffield, UK.

Thompson, M. R., \& Luck, G. (2012). Exploring relationships between pianists' body movements, their expressive intentions, and structural elements of the music. Musicae Scientiae, 16(1), 19-40. https://doi.org/10.1177/1029864911423457

Urchueguía, C. (2006). Critical editing of music and interpretation: Critical editions for critical musicians? Text, 16, 113-129.

Vines, B. W., Krumhansl, C. L., Wanderley, M. M., \& Levitin, D. J. (2006). Cross-modal interactions in the perception of musical performance. Cognition, 101(1), 80-113.

https://doi.org/10.1016/j.cognition.2005.09.003

Viney, L., \& Blom, D. (2015). Preparing stylistically challenging contemporary classical repertoire for performance: Interpreting Kumari. International Journal of Music Education, 33(1), 66-79.

https://doi.org/10.1177/0255761414528435 